\title{
CARACTERÍSTICAS ASSOCIADAS A VÍTIMAS DE BULLYING NAS ESCOLAS BRASILEIRAS
}

Andra Aparecida Dionízio BARBOSA

Marianne Silva SOARES ${ }^{2}$

Janeide Mendes PEREIRA ${ }^{3}$

\begin{abstract}
${ }^{1}$ Mestra em Ciências da Saúde e Enfermeira Docente da Universidade Estadual de Montes Claros; email: andrabh@hotmail.com

${ }^{2}$ Bióloga e discente do curso de Enfermagem da Universidade Estadual de Montes Claros; email: melrysnane@yahoo.com.br

32Discente do curso de Enfermagem da Universidade Estadual de Montes Claros; email: janeidempereira@ hotmail.com
\end{abstract}

Recebido em: 01/08/2016 - Aprovado em: 10/12/2017 - Disponibilizado em: 30/12/2017

\begin{abstract}
RESUMO
Introdução:O bullying é um tipo de violência que se caracteriza como um obstáculo ameaçador, no qual os jovens são excluídos, discriminados, agredidos e até machucados por outros. É um problema encontrado em todo o mundo. Objetivo: identificar, com base na literatura, as características associadas à vítima de bullying nas escolas brasileiras.Metodologia: Trata-se de uma revisão integrativa realizada na base de dados da Biblioteca Virtual de Saúde, utilizando os descritores "Adolescência" e "Bullying". Foram utilizados os filtros: texto completo, em língua portuguesa, últimos seis anos (2010-2015). Resultados: Este estudo apontou diversas características associadas à vítima de bullying nas escolas brasileiras e, portanto sintetizaram-se as seguintes categorias temáticas: Baixa autoestima, Fragilidade em relação ao agressor,Sexo feminino: mais vulnerável, Alunos de séries iniciais, Membro de família monoparental, Sem apoio, reagem violentamente, Associação positiva ao consumo de drogas e Apresentam sintomas emocionais.Conclusão:Obullyingé uma violência à saúde mental das vítimas. Portanto faz-se necessário o incentivo a pesquisas nesta área, pois o conhecimento pode estabelecer uma visão mais ampla e mais próxima da realidade.
\end{abstract}

Palavras-chave: Bullying; Violência; Adolescente; Adulto Jovem; Vítimas de Crime.

\section{CHARACTERISTICS ASSOCIATED WITH BULLYING VICTIMS IN BRAZILIAN SCHOOLS}

\begin{abstract}
Introduction: Bullying is a form of violence characterized as a threatening obstacle, in which the young people are excluded,discriminated against, assaulted and even hurt by others.It is a problem encountered worldwide. Objective: The aim of this paper is to identify, based on the literature, the characteristics associated with bullying victims in Brazilian schools. Methodology: This is an integrative review performed on the Biblioteca Virtual de Saúde database, using the descriptors "Adolescência" and "Bullying". The following filters were used: complete text, Portuguese language, published from 2010 to 2015. Results: This studypointedto several characteristics associated with bullying victims in Brazilian schools and the following thematic categories were set: low self steem, weakness against the aggressor, female sex: more vulnerable, students in early grades, one parent family members, no support, violent reactions, positive association with drugs consumption and emotional symptoms presented. Conclusion: Bullying is a violence to the victim's mental health. Therefore, researches in this area are encouraged, as knowledge can establish a broader and closer view of reality.
\end{abstract}

Keywords: Bullying; Violence; Teenagers; Young adult; Crime victims; 


\section{Introdução}

Atualmente há um aumento dos indicadores da violência no mundo: taxas de homicídios, conflitos étnicos, religiosos, raciais, índices de criminalidade e narcotráfico. Dessa forma houve um alargamento do entendimento da violência, uma reconceituação de suas peculiaridades pelos novos significados que o conceito assume. $\mathrm{O}$ que anteriormente eram práticas costumeiras de regulamentação das relações sociais, hoje essas formas de violência estão migrando da esfera do estritamente privado para sua consideração como fatos públicos, merecedores de sanção social e estamos nessa transição. Ainda que existam dificuldades para definir o que se nomeia como violência, alguns elementos consensuais sobre o tema podem ser delimitados como a noção de coerção ou força; o dano que se produz em indivíduo ou grupo de indivíduos pertencentes à determinada classe ou categoria social, gênero ou etnia. Assim há violência quando, em uma situação de interação, um ou vários atores agem de maneira direta ou indireta, maciça ou esparsa, causando danos a uma ou a mais pessoas em graus variáveis, seja em sua integridade física, seja em sua integridade moral, em suas posses, ou em suas participações simbólicas e culturais (WAISELFISZ, 2012).

Dentro da violência se destaca o "bullying", palavra vinda do inglês "bully" se assemelha ao termo em língua portuguesa "valentão" ou "machão", que se caracteriza como um obstáculo ameaçador, no qual os jovens são excluídos, discriminados, agredidos e até machucados por outros. Tal problema não é novo e pode "ser identificado" em todas as escolas das redes públicas ou privadas. Trata-se de insultos, apelidos cruéis, gozações, ameaças, acusações injustas, atuação de grupos que hostilizam a vida de outros levando-os à exclusão. O bullying é uma forma de violência que dificilmente acontece diante de testemunhas e, portanto, é de difícil identificação (LEÃO, 2010).

\section{Para Zottis (2012), o bullying} engloba uma série de tipos de violência interpessoal, na esfera social e ocorre em qualquer idade, mas no Brasil se refere à violência entre alunos no ambiente escolar. É um comportamento agressivo, ofensivo e repetitivo, é realizado por uma pessoa ou grupo contra outro(s) tem por intenção a humilhação e até mesmo o machucar em uma relação desigual de poder, está entrelaçado com transtornos mentais e consequências graves na vida adulta das vítimas e dos agressores. A prática do bullying por adolescentes demonstra um entrave na socialização, na construção da empatia e do autocontrole, que geralmente são formados no seio familiar.

Diante do exposto faz-se necessário o estudosobre a prática do bullying por adolescentes, com o objetivo de 
identificar,com base na literatura, as características associadas à vítima de bullying nas escolas brasileiras.

\section{Metodologia}

Foi realizada uma revisão integrativa, que é uma ferramenta importante no processo de comunicação dos resultados de pesquisas, pois proporciona uma síntese do conhecimento já produzido e serve de subsídio para a melhor a assistência à saúde. Além disso, revisão integrativa oferece aos profissionais de diversas áreas de atuação na saúde o acesso mais rápido aos resultados relevantes de pesquisas realizadas que auxiliam em condutas ou na tomada de decisão, proporcionando um conhecimento crítico (MENDES; SILVEIRA; GALVÃO, 2008).

Primeiramente identificou-se o tema "violência na prática do bullying por adolescentes na escola" e em seguida selecionou-se a questão norteadora para a pesquisa, que foi: Quais as características associadas às vítimas de bullying, de acordo com a literatura?

A busca por artigos foi realizada na base de dados da Biblioteca Virtual de Saúde (BVS), LILACS, Index Psicologia Periódicos técnico-científicos, MEDLINE, BBO - Odontologia, BDENF - Enfermagem. O período de busca foi durante os meses de abril, maio, e junho de 2015. Foram utilizados os descritores "Adolescência" e "Bullying" e encontrados 1.446 artigos. Após, passousepelos filtros: texto completo, em língua portuguesa, últimos seis anos (2010-2015). Encontraram-se27 artigos e, desses, somente 14 respondiam a questão norteadora.

Avaliaram-se os estudos incluídos na revisão integrativa. E a partir dos dados coletados fez-se a interpretação dos resultados, que foram apresentados de forma sintética em uma tabela. Em seguida, fez-se a categorização dos estudos, baseada na análise das informações extraídas dos mesmos.

\section{Resultados e Discussão}

O conhecimento documentado pela literatura investigada foi sintetizado nas seguintes categorias temáticas: Autoestima, Desequilíbrio de poder eagressões sofridas, Prevalência, Escolaridade e local da agressão,Estrutura familiar, Forma de reação e apoio a vítima de bullying, Uso de álcool/drogas e Sintomas.

\section{$\underline{\text { Baixa autoestima }}$}

Segundo Bandeira et al. (2010) a autoestima é talvez a variável mais crítica, afeta na forma como o adolescente lida com o ambiente e com a sociedade da qual faz parte. Os adolescentes com boa percepção de si mesmos são mais persistentes e fazem mais progressos diante de tarefas difíceis que aqueles com uma baixa autoestima. 
Para Wendt e Lisboa (2013, p.78)as vítimas são geralmente "identificadas como mais frágeis", com pouco ou nenhum recurso de enfrentamento. Adolescentes que se percebem como insatisfeitos com a imagem corporal apresentaram mais do que o triplo de chances de serem vítimas, já os estudantes com hábitos sedentários por mais de três horas por dia apresentaram 55\% mais chances de serem vitimas de bullyng e mais que o dobro de chances de serem agressores (RECH et al., 2013).

Em um estudo realizado por Moreno et al. (2012) as vítimas, avaliam sua aparência positivamente, gostam de se olhar no espelho, não ingerem bebida alcoólica, conversam com alguém quando tem algum problema e se consideram tímidas, entretanto têm facilidade de fazer amigos.

\section{$\underline{\text { Fragilidade em relação ao agressor }}$}

Para Silvaet al. (2014) há um desequilíbrio de poderentre as vítimas e agressores no contexto da intimidação, eles nunca praticam com alguém que tem a mesma forca que eles. Os adolescentes intimidadores demonstram falta de empatia com as vítimas, obtém prazer em irritar, controlar e tem a certeza de que não serão punidos (NASCIMENTO; MENEZES, 2013).

Quanto à forma ou tipo de agressão sofrida, Wendt e Lisboa (2013) referem que as agressões sofridas envolvem o uso de linguagem depreciativa, com conotações sexuais, de ódio e ameaça. Em outro estudo relata que o tipo de agressão é $75,1 \%$ verbal, $62,4 \%$ físicas, $23,8 \%$ emocionais, $6,3 \%$ racistas e $1,1 \%$ sexuais. Dentre as vítimas, $47,1 \%$ revelaram já ter provocado bullyingna escola (MOURA; CRUZ; QUEVEDO, 2011).

$$
\text { Zaine; Reis e Padovani (2010) }
$$

relatam que os comportamentos de autoria de bullying envolvemagressão física e ameaças aos colegas com chutes, empurrões, "xingos" e brincadeiras desagradáveis. Alunos com dificuldades de aprendizagem ou que obtivessem notas baixas eram alvo de agressões verbais, xingamentos e humilhações. As intimidações eram denominadas pelos autores de brincadeiras e por esse motivo, eram naturalizadas pelos docentes e alunos (NASCIMENTO; MENEZES, 2013). Entre os meninos as agressões físicas eram as formas mais frequentes, e entre as meninas predomina as agressões verbais, insultos e fofocas (MORENO et al., 2012).

\section{Sexo feminino: mais vulnerável}

A frequência de envolvimento em situações de violência é de $17,5 \%$ para o sexo masculino e $8,9 \%$ para o feminino, sendo estatisticamente diferente (ANDRADE et al., 2012). Quanto à prevalência a maioria (60\%) das vítimas é do sexo feminino (WENDT; LISBOA, 2013; MORENO et al., 2012). Já para Mendes (2011), obullying ocorre mais 
nos rapazes do que nas moças, tanto como agressores (72\%), quer como vitimas (51\%). Também, Moura; Cruz e Quevedo (2011), em sua amostra, constataram que $52,7 \%$ das vítimas eram do sexo masculino. Foi relacionado que o sexo masculino, possui problemas emocionais, de conduta, de hiperatividade e de relacionamento associados à vitimização ao bullying. Outro estudo aponta que os meninos apresentaram mais do que o dobro de chances de serem agressores em relação às meninas (RECH et al., 2013). Em um estudo realizado por Zaine; Reis e Padovani (2010) os resultados apontaram que $100 \%$ dos participantes admitiram haver sido tanto alvo quanto autores de bullying.

\section{$\underline{\text { Alunos de séries iniciais }}$}

Quanto à escolaridade, Mendes (2011) relata em seu estudo a ocorrência de vitimas do $6^{\circ}$ ano de escolaridade (58\%), sendo que sua amostra continha estudantes do $5^{\circ}$ e $6^{\circ}$ ano. Em outro estudo, 28,5\% das vítimas estavam entre 6 e 8 anos de idade; $32 \%$, entre 9 e 11 anos; e 39,6\%, entre 12 e 18 anos. Cursavam as quatro primeiras séries, $56,5 \%$ dos alunos; e o restante, da $5^{\mathrm{a}}$ à $8^{\mathrm{a}}$ série (MOURA; CRUZ; QUEVEDO, 2011). De acordo com Lamas; Freitas e Barbosa (2013) o bullying esta presente em todos os anos escolares, com uma porcentagem maior de vítimas no $5^{\circ}$ ano, agressores no $7^{\circ}$ ano e de vitimas agressoras no $6^{\circ}$ ano.
Em relação ao local da agressão, a maioria das agressões $(55,1 \%)$ acontece no pátio da escola, (MOURA; CRUZ; QUEVEDO, 2011). De acordo com Lamas; Freitas e Barbosa (2013) as agressões ocorrem, nas salas de aula, no recreio, corredores/escadas e banheiros, e em todas as séries a sala de aula é considerada um dos locais onde as práticas de bullying ocorrem frequentemente.

\section{$\underline{\text { Membro defamília monoparental }}$}

Já quanto à estrutura familiar, Mendes (2011) afirma que os estudantes agressores provêm maioritariamente de famílias do tipo monoparental $(49,6 \%)$ e as vítimas de famílias nucleares $(58,6 \%)$. Em um estudo realizado por Moreno et al. (2012)a mãe era a principal responsável pelo aluno $(73,3 \%)$ nas instituições de ensino publicas e particulares, $(33,9 \%)$ dos estudantes relataram ter pais analfabetos ou com a $3^{\circ}$ série do ensino fundamental. Comparativamente, obteve-se $(46 \%)$ de pais analfabetos ou com até $3^{\mathrm{a}}$ série na instituição pública e $50,4 \%$ de pais com ensino superior completo entre os estudantes da rede particular de ensino. Verificou-se ausência de diálogo no âmbito familiar, a maioria dos adolescentes relatou raramente conversar com os pais sobre as dificuldades vivenciadas em seu cotidiano. É importante que a família estimule o diálogo com seus filhos, de forma a proporcionandolhes liberdade e autonomia, impedindo assim, 
que se tornem sujeitos passivos em suas relações sociais, fazendo-o uma possível vítima do bullying.

\section{$\underline{\text { Sem apoio, reagem violentamente }}$}

Em relação à forma de reação da vítima ao agressor, no momento em que este as agride, verificou-se que $41,7 \%$ das vítimas, reagem agredindo também o agressor e 36,5\% das vítimas optam por não contar a ninguém que foram agredidas (MENDES, 2011).

Quanto ao apoio à vítima do bullying, quando questionadas sobre quem mais as apoia, quando são agredidas na escola na presença de terceiros, $63 \%$ das vítimas referiram ninguém e $37 \%$ respondeu os colegas da própria turma. Os estudantes de outras turmas $(2 \%)$, os professores $(4,2 \%)$ e outros funcionários da escola (2\%), foram apontados pelas vítimas, como aqueles que menos as apoiaram quando agredidas na presença dos mesmos (MENDES, 2011).

\section{Associação positiva ao consumo de drogas}

Com relação ao uso de drogas adolescentes do sexo masculino apresentaram maiores prevalências de uso de drogas ilícitas e bullyingem relação à adolescentes do sexo feminino. Os principais fatores de risco associados ao consumo de drogas ilícitas por adolescentes são: contexto familiar, consumo de bebidas alcoólicas, baixa escolaridade, tabagismo, vinculo escolar baixo, ocorrência de reprovações escolares, influência de amigos, e comportamento antissocial (ANDRADE et al., 2012).

Apresentam sintomas emocionais

Parece que há uma relação entre a vivência de bullying escolar e o desenvolvimento de sintomas de Transtorno de Estresse Pós-Traumático (TEPT) podendo apresentar maior vulnerabilidade para apresentar TETP (ALBUQUERQUE; WILLIAMS; D'AFFONSECA, 2013).

Wendt e Lisboa (2013) relatam o desenvolvimento de sintomas de depressão e ansiedade como consequências ou fator de risco adicional para adolescentes vítimas de bullying. Além disso, sentimentos de desamparo e descontrole, são sintomas inerentes à vitimização crônica e, o que pode demonstrar perigo e ameaça suficientemente para produzir sintomas de TEPT, resultando em ruminações cognitivas e lembranças intrusivas, como sonhos e pensamentos sobre as interações negativas, evitando situações associadas à vitimização e reatividade fisiológica.

Outro estudo relatou que dos adolescentes entrevistados em seu estudo que tiveram dificuldades com a obesidade, $78,8 \%$ tinham transtornos emocionais como bullying, ansiedade e irritabilidade (NOGUEIRA; ZAMBON, 2013). Estudos mostram que as vítimas de bullying não buscam atendimento especializado, o que pode causar prejuízos sérios, ou mesmo irreversíveis, como 
suicídios, homicídios e massacres em escolas (WENDT; LISBOA, 2013).

\section{Considerações finais}

A revisão bibliográfica realizada neste estudo apontou que são diversas as características associadas à vítima de bullying nas escolas brasileiras. Verificou-se que as vítimas são geralmente identificadas como mais frágeis, que se percebem como insatisfeitas com a imagem corporal, apesar de algumas avaliarem a sua imagem positivamente, gostam de se olhar no espelho e se consideram tímidas, entretanto têm facilidade de fazer amigos. Quanto à prevalência, a maioria das vítimas é do sexo feminino e a maioria das agressões acontece no pátio da escola, recreio, corredores, banheiros ou em sala de aula com diversos anos de escolaridade, com uma porcentagem maior de vítimas no quinto ano, agressores no sétimo e de vitimas agressoras no sexto ano.

O tipo de agressão sofrida envolve o uso de linguagem depreciativa, com conotações sexuais, de ódio e ameaça. Ocorre agressão verbal, físicas, emocionais e racistas. As vítimas reagem agredindo os agressores ou se calam, afirmam em sua maioria que não se percebem apoiadas por ninguém. Há uma prevalência do uso de drogas ilícitas por adolescentes do sexo masculino e bullyingem relação a adolescentes do sexo feminino.

As vítimas pertencem a famílias nucleares, há uma relação entre a vivência de bullyingescolar e o desenvolvimento de TEPT, depressão, ansiedade, sentimentos de desamparo e descontrole, sonhos e pensamentos sobre as interações negativas, além de dificuldades com a obesidade.

Obullyingé uma violência à saúde mental das vítimas. Portanto faz-se necessário o incentivo a pesquisas nesta área, pois o conhecimento pode estabelecer uma visão mais ampla e mais próxima da realidade. Dessa forma, poderá criar maior subsídio para uma intervenção mais eficaz contra $o$ bullying, englobando, por exemplo, a enfermagem e a psicologia nas escolas brasileiras. $\mathrm{O}$ apoio multiprofissional auxilia na prevenção de agravos e promoção da saúde dos jovens. A identificação do problema, intervenção poderão acontecer de forma precoce, de maneira que as possíveis consequências pós-traumáticas futuras possam ser minimizadas.

\section{Referências}

ALBUQUERQUE, Paloma Pegolo de; WILLIAMS, Lúcia Cavalcanti de Albuquerque; D'AFFONSECA, Sabrina Mazo. Efeitos tardios do bullying e transtorno de estresse pós-traumático: uma revisão crítica. Psic.: Teor. e Pesq., Brasília, v. 29, n. 1, p. 91-98, mar. 2013. Disponível em: <http://dx.doi.org/10.1590/S01023772201300 0100011 >. Acesso em: 22 jun. 2015.

ANDRADE, Silvania Suely Caribé de Araújo; YOKOTA, Renata Tiene de Carvalho; SÁ, NaízaNayla Bandeira de; SILVA, Marta Maria Alves da;ARAÚJO, Wildo Navegantes de; MASCARENHAS, 
Márcio Dênis Medeiros; MALTA, Deborah Carvalho.Relação entre violência física, consumo de álcool e outras drogas e bullying entre adolescentes escolares brasileiros. Cad. Saúde Pública, Rio de Janeiro, v. 28, n. 9, p. 1725-1736, set. 2012. Disponível em: <http://dx.doi.org/10.1590/S0102311X2012000900011>. Acesso em: 22 jun. 2015.

BANDEIRA, Cláudia de Moraes; HUTZS, Claudio Simon. As implicações do bullying na auto-estima de adolescentes. Rev.

Semestral da Associação Brasileira de Psicologia Escolar e Educacional, São

Paulo, v. 14, n. 1, jan./jun. de 2010.

Disponível

em:<http://www.scielo.br/pdf/pee/v14n1/v14 n1a14>. Acesso em: 22 jun. 2015.

LAMAS, Cristina Alves; FREITAS, Eduarda Rezende; BARBOSA, Altemir José Goncalves. Bullying e Relação ProfessorAluno: Percepções de Estudantes do Ensino Fundamental. Psico, Porto Alegre, PUCRS, v. 44, n. 2, p. 263-272, abr./jun. 2013.

Disponível em:<http://revistaseletronicas .pucrs.br/ojs/index.php/ revistapsico/ article/view/11738/95>. Acesso em: 20 jun. 2015.

LEÃO, Letícia Gabriela Ramos. O fenômenobullying no ambiente escolar. Rev. FACEVV, Vila Velha, n. 4, p. 119-135, jan./jun. 2010. Disponível em:

<http://www.facevv.edu.br/Revista/04/O\%20 FEN\%C3\%94MENO\%20BULLYING\%20N O\%20AMBIENTE\%20ESCOLAR\%20$\%$ 20leticia\%20gabriela.pdf $>$. Acesso em: 20 jun. 2015.

MENDES, Carla Silva. Prevenção da violência escolar: avaliação de um programa de intervenção. Rev. Esc. Enferm. USP, São Paulo, v. 45, n. 3, p. 581-588, jun. 2011.

Disponível em:

<http://dx.doi.org/10.1590/S008062342011000300005>. Acesso em 22 jun. 2015.
MENDES, Karina Dal Sasso; SILVEIRA, Renata Cristina de Campos Pereira; GALVÃO, Cristina Maria. Revisão Integrativa: Método de Pesquisa para a Incorporação de Evidências na Saúde e na Enfermagem. Texto Contexto Enferm., Florianópolis, v. 17, n.4, p. 758-64,out./dez. 2008. Disponível em: $<$ http://www.scielo.br/scielo.php?script=sci_a rttext\&pid=S010407072008000400018>. Acesso em: 20 jun. 2015.

MORENO, Emilly Anne Cardoso; SILVA, Amanda Pereira da; FERREIRA, Galdência Amaro; SIVA, Felicialle Pereira da; FRAZÃO, Iracema da Silva; CAVALCANTI, Ana Márcia Tenório de Souza. Perfil epidemiológico de adolescentes vítimas de bullyingem escolas públicas e privadas. Rev. Enferm. UERJ, Rio de Janeiro, v.20, n. 2, p. 808-813, dez. 2012. Disponível em: $<$ http://www.facenf.uerj.br/v20nesp2/v20e 2a19.pdf $>$. Acesso em: 20 jun. 2015.

MOURA, Danilo Rolim de; CRUZ, Ana Catarina Nova; QUEVEDO, Luciana de Ávila. Prevalência e características de escolares vítimas de bullying. J. Pediatr. Rio J., Porto Alegre, v. 87, n. 1, p. 19-23, fev. 2011. Disponível em: $<$ http://www.scielo.br/scielo.php?script=sci_ arttext\&pid=S002175572011000100004>. Acesso em: 20 jun. 2015.

NASCIMENTO, Alcione Melo Trindade do; MENEZES, Jaileila de Araújo. Intimidações na adolescência: expressões da violência entre pares na cultura escolar. Psicol. Soc., Belo Horizonte, v.25, n.1, p. 142-151, 2013. Disponível em: $<$ http://dx.doi.org/10.1590/S010271822013000100016>. Acesso em: 22 jun. 2015.

NOGUEIRA, Thais Florence D.; ZAMBON, Mariana Porto. Razoes do abandono do tratamento de obesidade por crianças e adolescentes. Rev. Paul. Pediatr., São Paulo, v. 31, n. 3, p. 338-343, set. 2013. Disponível em: <http://dx.doi.org/10.1590/S0103- 
05822013000300010>. Acesso em: 22 jun. 2015.

RECH, Ricardo R.; HALPERN,Ricardo; TEDESCO, Andressa; SANTOS, Diego F. Prevalência e características de vítimas e agressores de bullying. J. Pediatr. Rio J., Porto Alegre, v. 89, n. 2, p. 164-170, abr. 2013. Disponível em:

$<$ http://www.scielo.br/scielo.php?script=sci_a rttext\&pid=S002175572013000200010\&lng= en\&nrm=iso>. Acesso em: 22 jun. 2015.

SILVA, Jorge Luiz da; OLIVEIRA, Wanderlei Abadio de; BAZON, Marina Rezende; CECILIO, Sálua. Bullying: Conhecimentos, Atitudes e Crenças de Professores.Psico, Porto Alegre, PUCRS, v. 45, n. 2, p. 147-156, abr./jun. 2014.

Disponível em: <http://revistaseletronicas .pucrs.br/ojs/ index.php/revistapsico/ article/view/12683/11704>. Acesso em: 22 jun. 2015.

WENDT, Guilherme Welter; LISBOA, Carolina Saraiva de Macedo. Agressão entre pares no espaço virtual: definições, impactos e desafios do cyberbullying. Psicol. clin., Rio de Janeiro , v. 25, n. 1, p. 73-87, jun. 2013. Disponível em:

$<$ http://dx.doi.org/10.1590/S0103-

56652013000100005>. Acesso em: 22 jun. 2015.

ZAINE, Isabela; REIS, Maria de Jesus Dutra; PADOVANI, Ricardo da Costa.

Comportamentos de bullying e conflito com a lei. Estud. Psicol. (Campinas), Campinas, v.27, n.3, p. 375-382, set. 2010. Disponível em: <http://dx.doi.org/10.1590/S0103-

166X2010000300009>. Acesso em: 22 jun. 2015.

ZOTTIS, Graziela Aline Hartmann. Bullying na adolescência: associação entre práticas parentais de disciplina e comportamento agressivo na escola. Porto Alegre, BR- RS, 2012. 71 p. Originalmente apresentada como dissertação de Mestrado, Universidade Federal do Rio Grande do Sul, 2012.

Disponível em: <http://www.lume.ufrgs.br/handle/10183/489 76>. Acesso em: 22 jun. 2015 